\title{
Polymorphism in the TP63 gene imparts a potential risk for leukemia in the North Indian population
}

\author{
Amrita Bhat ${ }^{1}$, Gh. Rasool Bhat ${ }^{1}$, Sonali Verma ${ }^{1}$, Ruchi Shah ${ }^{1}$, Ashna Nagpal ${ }^{1}$, \\ Bhanu Sharma ${ }^{1}$, Divya Bakshi ${ }^{1}$, Jyotsna Suri ${ }^{2}$, Supinder Singh ${ }^{3}$, Mukesh Tanwar ${ }^{4}$, \\ Samantha Vaishnavi ${ }^{5}$, Audesh Bhat ${ }^{6}$, Rakesh Kumar ${ }^{1}$
}

1. Cancer Genetics Research Group, School of Biotechnology, Shri Mata Vaishno Devi University, Katra, J\&K, India, 182320.

2. Department of Pathology, GMC, Jammu, India.

3. Department of Medicine, ASCOMS, Sidhra, J\&K, India, 182320.

4. Departments of Genetics, Maharishi Dayanand University, Rohtak, Haryana, India.

5. Department of Botany, Central University of Jammu, J\&K, India.

6. Centre for Molecular Biology, Central University of Jammu, J\&K, India.

\begin{abstract}
Background: The role of single nucleotide polymorphism rs10937405 (C>T) of the TP63 gene in cancer including leukemia has previously been studied in different world populations; however, the role of this variant in leukemia in the North Indian population of Jammu and Kashmir is still unknown.

Objectives: In the present study, we investigated the association of genetic variant rs10937405 with leukemic in the Jammu and Kashmir population.

Methods: A total of 588 subjects, (188 cases and 400 controls) were recruited for the study. The rs10937405 variant was genotyped by using the real-time based TaqMan assay.

Results: A statistically significant association was observed between the rs10937405 and leukemia [OR of 1.94 (95\% CI 1.51-2.48), $\mathrm{p}=1.2 \mathrm{x} 10-6]$.

Conclusion: The current study concludes that the rs10937405 variant is a risk factor for the development of leukemia in the population of Jammu and Kashmir, North India. However, it would be interesting to explore the contribution of this variant in other cancers as well. Our findings will help in the development of diagnostic markers for leukemia in the studied population and potentially for other North Indian populations.

Keywords: Single Nucleotide Polymorphism (SNPs); Leukemia; North Indian population; Tumour suppressor (TP63); Linkage Disequilibrium (LD); Genome wide association studies (GWAS); Jammu and Kashmir (J \&K).

DOI: https://dx.doi.org/10.4314/ahs.v21i3.34

Cite as: Bhat A, Bhat GR, Verma S, Shah R, Nagpal A, Sharma B, et al. Polymorphism in the TP63 gene imparts a potential risk for leukemia in the North Indian population. Afri Health Sci. 2021;21(3). 1243-1249. bttps:/ / dx.doi.org/10.4314/ abs.v21i3.34
\end{abstract}

\section{Introduction}

Leukemia ranks among the top most cancers in the world with an estimated 3,00,000 new cases $(2.8 \%$ of all new cancer cases and 3.8\% deaths) diagnosed every year globally ${ }^{1,2}$. In India, leukemia is ranked ninth with a ratio of 1.56:1.09 in males and females ${ }^{3}$. In India, a total

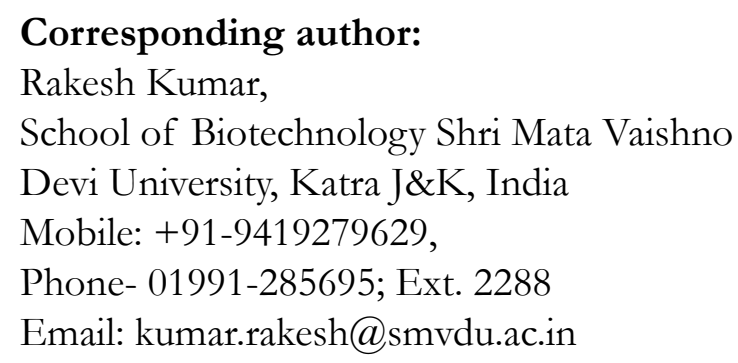

of more than 10,000 new cases of childhood leukemia have been reported annually ${ }^{4}$. Among North Indian populations, the population of Jammu and Kashmir is found to be at higher risk, with high mortality rate associated with different cancers ${ }^{5}$. The incidence of leukemia in Jammu and Kashmir has increased rapidly about $5.07 \%$ in the previous decade ${ }^{6}$. The population of northern part of Jammu and Kashmir state practice endogamy, thus preserving the gene pools that result in the increase of homozygosity. This factor has been documented as an inherited genetic factor that can contribute to the etiology of leukemia ${ }^{7}$. Leukemia is multifactorial in origin which can be caused by both genetic as well as non-genetic factors. Genome-wide 
association studies (GWAS) have advanced our understanding of susceptibility to leukemia; however, much of the heritable risk factors remain unidentified. Previous GWAS have suggested a polygenic susceptibility to leukemia, identifying SNPs in different loci influencing leukemia risk such as, 7p12.2 (IKZF1), 9p21.3 (CDKN2A), 10p12.2 (PIP4K2A), 10q26. ${ }^{13}$ (LHPP), 12q23.1 (ELK3), 10p14 (GATA3), 10q21.2 (ARID5B), and 14q11.2 (CEBPE) $)^{8-12}$. Recently, GWAS has found a strong association of variant rs10937405 of TP63 with lung cancer in Korean population ${ }^{13}$. The TP63 gene is a homolog of the tumor suppressor gene TP53, located on chromosome $3 \mathrm{q} 27-28$ region, which is a member of transcription factor. This rs10937405 variant could probably affect the expression of other genes and can increase the risk of leukemia. In the current study, we aimed to explore the association of variant rs10937405 of TP63 with leukemia in the North Indian population of Jammu and Kashmir.

\section{Materials and methods \\ Ethics statement}

The Institutional Ethics Review Board (IERB) of Shri Mata Vaishno Devi University (SMVDU) approved the study through notification number SMVDU/ IERB/16/41. All the details of cases and controls were recorded in a predesigned proforma and a written informed consent was obtained from all the participants. All experimental procedures were conducted according to the guidelines and regulations set by the IERB, SMVDU.

\section{Sampling}

A total of 588 subjects were recruited for the study, of which 188 were the leukemic cases collected from the different hospitals of Jammu and Kashmir after ethical approval and informed consent and 400 were age and sex-matched healthy controls. All cases were histopathologically confirmed by pathologist, GMC, Jammu. The genomic DNA was isolated from the blood samples using Qiagen DNA Isolation kit (Cat. No. 51206). Agarose gel electrophoresis was used to analyse the quality of the genomic DNA and quantification was performed using UV spectrophotometer.

\section{Genotyping}

Genotyping of variants rs10937405 of TP63 was performed using the TaqMan allele discrimination assay MX3005p labeled with VIC (Victoria Green Fluorescent Protein) and FAM (Fluorescein amidites) dyes (Thermo Fisher Scientific) and UNG Master Mix (Applied Bio-systems, USA). The Volume of the total PCR reaction was $10 \mu \mathrm{l}$, comprising of $2.5 \mu \mathrm{l}$ of TaqMan UNG Master Mix, $0.25 \mu \mathrm{l}$ of the probe, $3 \mu \mathrm{l}$ DNA (5ng/ $\mu \mathrm{l})$ and $4.25 \mu \mathrm{l}$ nuclease-free water added together to make the final volume. The thermal conditions adopted were 10 minutes at $95^{\circ} \mathrm{C}, 40$ cycles of $95^{\circ} \mathrm{C}$ for $15 \mathrm{sec}$ onds and $60^{\circ} \mathrm{C}$ for $1 \mathrm{~min}$. All the samples were run in a 96-well plate with three no template controls (NTCs). The post PCR detection system was used to measure allele-specific fluorescence. A total of 93 random samples each from cases and controls were picked and re-genotyped for cross-validation of the genotyping calls and the concordance rate was $100 \%$.

\section{Statistical analysis}

Statistical analyses of the data were performed by using SPSS software (v.20; Chicago, IL). Chi-square ( $\chi 2)$ was performed and genotyping frequencies were also tested. All samples were following the Hardy-Weinberg equilibrium. Binary Logistic Regression was used to estimate OR at 95\% confidence interval (CI) and the respective level of significance was estimated as $\mathrm{p}$-value.

\section{Results}

We recruited a total of 588 subjects, out of which 188 were leukemia patients (cases) and 400 healthy (controls). Among the cases, 56\% were males and 44\% were females and among the controls, $68 \%$ were males and $32 \%$ were females, suggesting that the frequency of Leukemia is higher among males in the $\mathrm{J} \& \mathrm{~K}$ population. The mean age in cases were $40.51( \pm 14.67)$ years and that of controls 50.76 ( \pm 13.30$)$. The average BMI of cases $(21.21 \pm 6.08)$ and controls $(24.21 \pm 5.06)$ as shown in Table 1. 
Table 1: Clinical characteristics for cases and controls

\begin{tabular}{|c|c|c|c|}
\hline Characteristics & Cases (Leukemia patients & Controls & $p$-value \\
\hline $\begin{array}{c}\text { Age } \\
\text { *(in years) }\end{array}$ & $\begin{array}{c}40.51 \\
\pm 14.67\end{array}$ & $\begin{array}{c}50.76 \\
\pm 13.30\end{array}$ & $<0.01$ \\
\hline Gender (in \%) & $\begin{aligned} F & =44 \\
M & =56\end{aligned}$ & $\begin{array}{l}\mathrm{F}=32 \\
\mathrm{M}=68\end{array}$ & - \\
\hline BMI Kg/m² & $\begin{array}{l}21.21 \\
\pm 6.08 \\
\end{array}$ & $\begin{array}{l}24.21 \\
\pm 5.06 \\
\end{array}$ & $<0.001$ \\
\hline \multicolumn{4}{|l|}{ Smoking (\%) } \\
\hline $\begin{array}{l}\text { YES } \\
\text { NO }\end{array}$ & $\begin{array}{l}60 \\
40\end{array}$ & $\begin{array}{l}24 \\
76\end{array}$ & \\
\hline \multicolumn{4}{|l|}{ Alcohol (\%) } \\
\hline $\begin{array}{l}\text { Yes } \\
\text { No }\end{array}$ & $\begin{array}{l}50 \\
50\end{array}$ & $\begin{array}{l}12 \\
88\end{array}$ & \\
\hline
\end{tabular}

*Corrected for age, gender, BMI, alcohol consumption, and smoking

The allele frequency distribution of the variant suggesting that allele $T$ is causing risk. We observed that rs10937405 of TP63 between cases and controls is genetic allele T of variant rs10937405 of TP63 is signifsummarized in Table 2 . In the current study, $\mathrm{T}$ is pres- icantly associated with leukemia ( $\mathrm{p}$ value $=1.2 \times 10-6$ ), ent in more cases (0.62) than in controls (0.54), hence with H.W. $\mathrm{E}=0.974$.

Table 2: Allelic frequency distribution between cases and controls

\begin{tabular}{|c|c|c|c|c|c|c|}
\hline SNP ID & $\begin{array}{c}\text { Cases }(\%) \\
(\mathrm{N}=188)\end{array}$ & $\begin{array}{c}\text { Controls }(\%) \\
\qquad(\mathrm{N}=400)\end{array}$ & $\begin{array}{l}\text { Allele OR* } \\
(95 \% \text { CI })\end{array}$ & $\begin{array}{l}\text { Risk } \\
\text { Allele }\end{array}$ & $p$-value* & Total $H W E$ \\
\hline $\begin{array}{c}\text { rs109374 } \\
05\end{array}$ & $\begin{array}{l}\mathrm{C}=0.38 \\
\mathrm{~T}=0.62\end{array}$ & $\begin{array}{l}\mathrm{C}=0.46 \\
\mathrm{~T}=0.54\end{array}$ & $\begin{array}{c}1.94(1.51- \\
2.48)\end{array}$ & $T$ & $\begin{array}{l}1.2 \times \\
10-6\end{array}$ & 0.974 \\
\hline
\end{tabular}

*Corrected for age, gender, BMI, alcohol consumption and smoking.

To observe the maximum effect of allele $\mathrm{T}$, we evaluated the association by using dominant model. The OR observed was $1.6(0.94-2.4)$ at $95 \% \mathrm{CI}$ in leukemia corrected for age, gender and BMI. Furthermore, we have evaluated the variant rs10937405 of TP63 by applying other genetic models as per the risk allele and the results observed were showing positive association of variant in all the three models in case of Leukemia as shown in Table 3.

Table 3: Showing the association of variant rs10937405 of Tp63 with leukemia in North Indian population using genetic models

\begin{tabular}{|l|l|l|c|c|c|}
\hline SNP ID & R A & Genetic Models & Genotype & $p$-value & OR (95\%CI) \\
\hline \multirow{3}{*}{ rs10937405 } & \multirow{3}{*}{$\boldsymbol{T}$} & Dominant model & TT +TC Vs CC & 0.08 & $1.6(0.94-2.4)$ \\
\cline { 3 - 6 } & & Recessive Model & TT vs TC + CC & 0.001 & $1.7(0.8-3.54)$ \\
\cline { 3 - 6 } & & Additive Model & TT vs TC vs CC & 0.02 & $1.48(1.01-2.16)$ \\
\hline
\end{tabular}

*Corrected for Age, Gender and BMI

To evaluate the association of rs10937405 with different subtypes of leukemia, statistical analyses was performed on the allelic distribution within these subtypes as shown in table 4 . The variant rs10937405 of TP63 was found significantly associated with all four subtypes of the leukemia ( $\mathrm{p}$-value $=0.002,0.0001,0.032$, and 0.034 for ALL, AML, CML, and CLL, respectively). 
Table 4: Genetic association of different subtypes of leukemia with the variant rs10937405 variant

\begin{tabular}{|c|c|c|c|c|c|}
\hline \multirow[t]{2}{*}{ Genotype } & \multicolumn{4}{|c|}{ Histological Subtype (Leukemia) } & \multirow{2}{*}{$\begin{array}{l}\text { Controls } \\
\begin{array}{l}\text { Controls } \\
(\mathrm{n}=400)\end{array}\end{array}$} \\
\hline & $\begin{array}{c}\text { CML } \\
(\mathrm{n}=93)\end{array}$ & $\begin{array}{c}\text { AML } \\
(n=30)\end{array}$ & $\begin{array}{c}\text { ALL } \\
(n=35)\end{array}$ & $\begin{array}{c}\text { CLL } \\
(\mathrm{n}=\mathbf{3 0})\end{array}$ & \\
\hline $\mathrm{CC}$ & 25 & 12 & 11 & 08 & 64 \\
\hline CT & 46 & 10 & 15 & 10 & 190 \\
\hline TT & 22 & 8 & 09 & 12 & 146 \\
\hline TOTAL & 93 & 30 & 35 & 30 & 400 \\
\hline p-value & 0.002 & 0.0001 & 0.032 & 0.034 & - \\
\hline
\end{tabular}

The calculated OR under different models as given in table 1 showed significant association of rs10937405 with leukemia. The allelic OR was 1.94 (1.51-2.48 at $95 \% \mathrm{CI}, \mathrm{p}=1.2 \times 10-6)$. Under additive model the OR was $1.48(1.01-2.16)$, at $95 \% \mathrm{CI}, \mathrm{p}=0.02$, under the recessive model the OR was 1.7(0.8-3.54), at 95\% CI, $\mathrm{p}=0.001$. All values were corrected for age, gender, BMI, smoking and alcohol consumption.

\section{Discussion}

In the present study, association of the variant rs10937405 of TP63 with leukemia was explored in the North Indian population. Previously, the association of this variant was reported in the population groups of $\mathrm{Japan}^{14}$ and Korea ${ }^{13}$, where ' $\mathrm{C}$ ' allele was found to be the risk allele. Most interestingly in the present study, it was found that ' $T$ ' which is a wild type allele was a risk factor in the studied population. In various GWAS in different ethnic populations, the rs10937405 variant was found to be associated with lung cancer risk in the

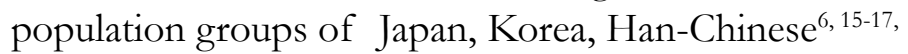
. The variant was found associated with lung carcinoma among Asian females in absence of tobacco smoking ${ }^{18}$, but showed significant association with smoking in UK Population. The variant shows association with lung cancer with significance association with smoking ${ }^{19}$. We did not come across any work which has found any association between aleukemia risk and coal and further more we evaluated the role of cigarette smoking in leukemia. And our study is the first to find the association of smoking with leukemia. Though In future, this genetic variant can also be explored in different ethnic populations for a variety of reasons, including differences in their allele frequency and in both the genetic and environmental backgrounds that interact with the variant.

The TP63 gene plays an important role in cell proliferation, apoptosis, development, differentiation, senescence, ageing, and response to cellular stress. TP63 contains two transcriptional start sites leading to p63 isoforms either containing (TP63) or lacking ( $\Delta$ Np63) , the trans-activation domain ${ }^{20}$. TP63 isoforms possesses strong transactivation activity on p53 responsive promoters, whereas $\Delta \mathrm{Np} 63$ isoforms are able to outcompete p53 for binding to p53- responsive promoters and repress gene expression. TP63 protein contains N-terminal TA domain that is $22 \%$ homologous, while $\Delta \mathrm{Np} 63$ isoforms are transcribed from alternative promoter within third intron ${ }^{21}$. The 14 unique $\mathrm{N}$-terminal amino acid residues in $\Delta \mathrm{Np} 63$ isoforms have shown to possess transactivation activity. TP63 expression has been reported in blast crisis in chronic myelogenous leukemia ${ }^{22}$ follicular lymphoma (FL), diffuse large B-cell lymphoma (DLBCL) ${ }^{23}$ and, isolated cases of chronic lymphocytic leukemia, marginal cell lymphoma. In some studies, Tp63 was found over expressed and hypo methylated in CLL subtypes of leukemia ${ }^{24}$.

However, accumulation of DNA damage and deficient response to genotoxic stress contributes to an earlier progression of leukemia. DNA damage activates c-Abl and then activates TP63 to mediate cell death. TP63 is responsible for inducing transcription of pro-apoptotic family members PUMA (p53 upregulated modulator of apoptosis) and NOXA, which then bind to BAX/BAK and trigger apoptosis. Puma can also be activated independently of p53 and thus plays an important role in p53-independent apoptosis. The p53 homolog p73 can also regulate Puma expression by binding to the same p53-responsive elements in the Puma promoter. Puma is believed to bind Bak through Bid and Bim. Noxa is less effective than Puma in p53-mediated apoptosis, for Puma (like Bim) can bind to all the anti-apoptotic Bcl-2 family members, whereas Noxa antagonizes only Mcl-1 and A1. Nevertheless, the functional overlap of Noxa and Puma in apoptosis caused by DNA damage indicates that, to some extent, they may cooperate in the progress of apoptosis. However, if there is a mutation in the TP63, it inhibits the apoptosis which leads in the progression of leukemia as shown in Figure 1. 


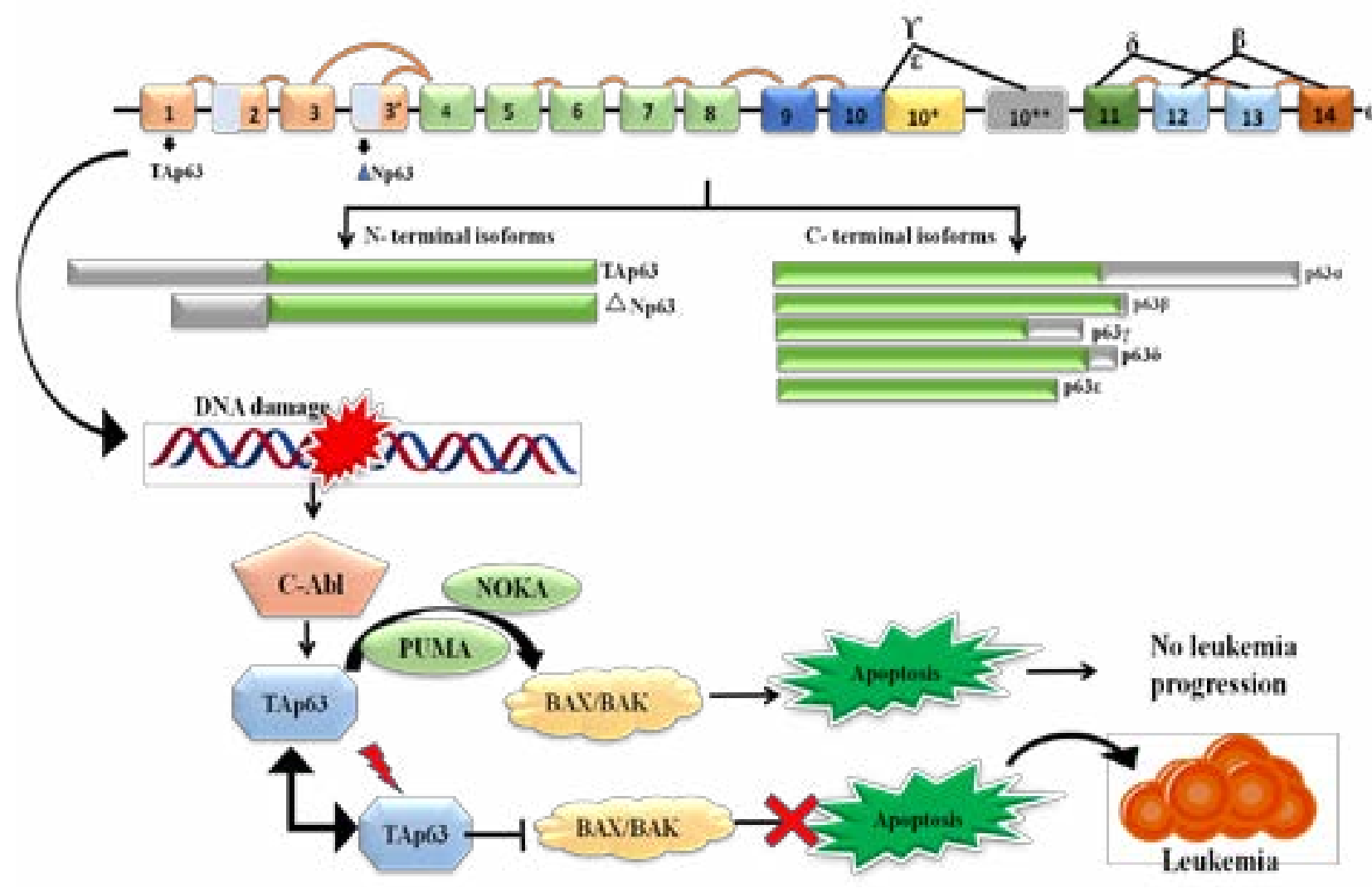

Figure 1: Showing the Hypothesized pathway of TP63 which leads to DNA damage and targeting apoptotic pathway where it leads to progression of leukemia.

Tp63 is shown to interact with many genes as described in String tool software v10.5

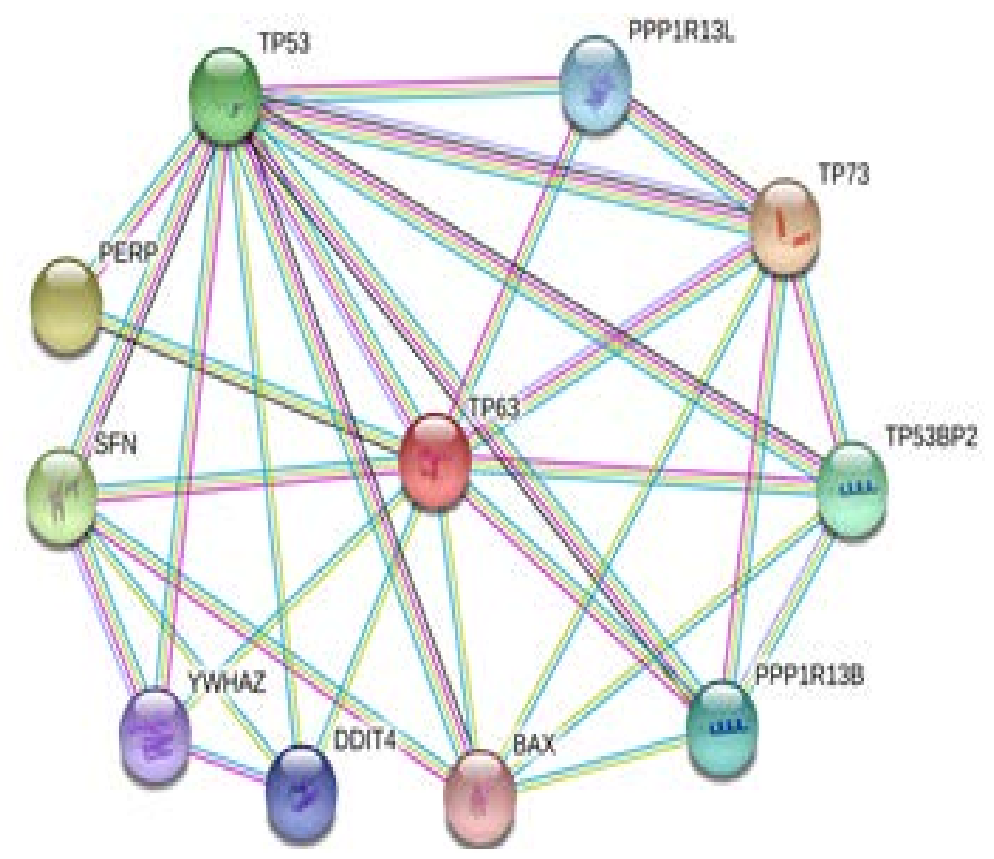

Supplementary Figure S1: Showing the interaction of TP63 with other genes by string tool software. More the thickness of nodes more is the relationship among the genes, less the thickness of nodes less will be the relationship among these genes.

Besides, this genetic variant has putative regulatory effect (SNIPA online tool) as shown in figure 2, thus pol- ymorphism in any of the region could possibly affect the neighboring SNPs and disturb the physiology of genes. 


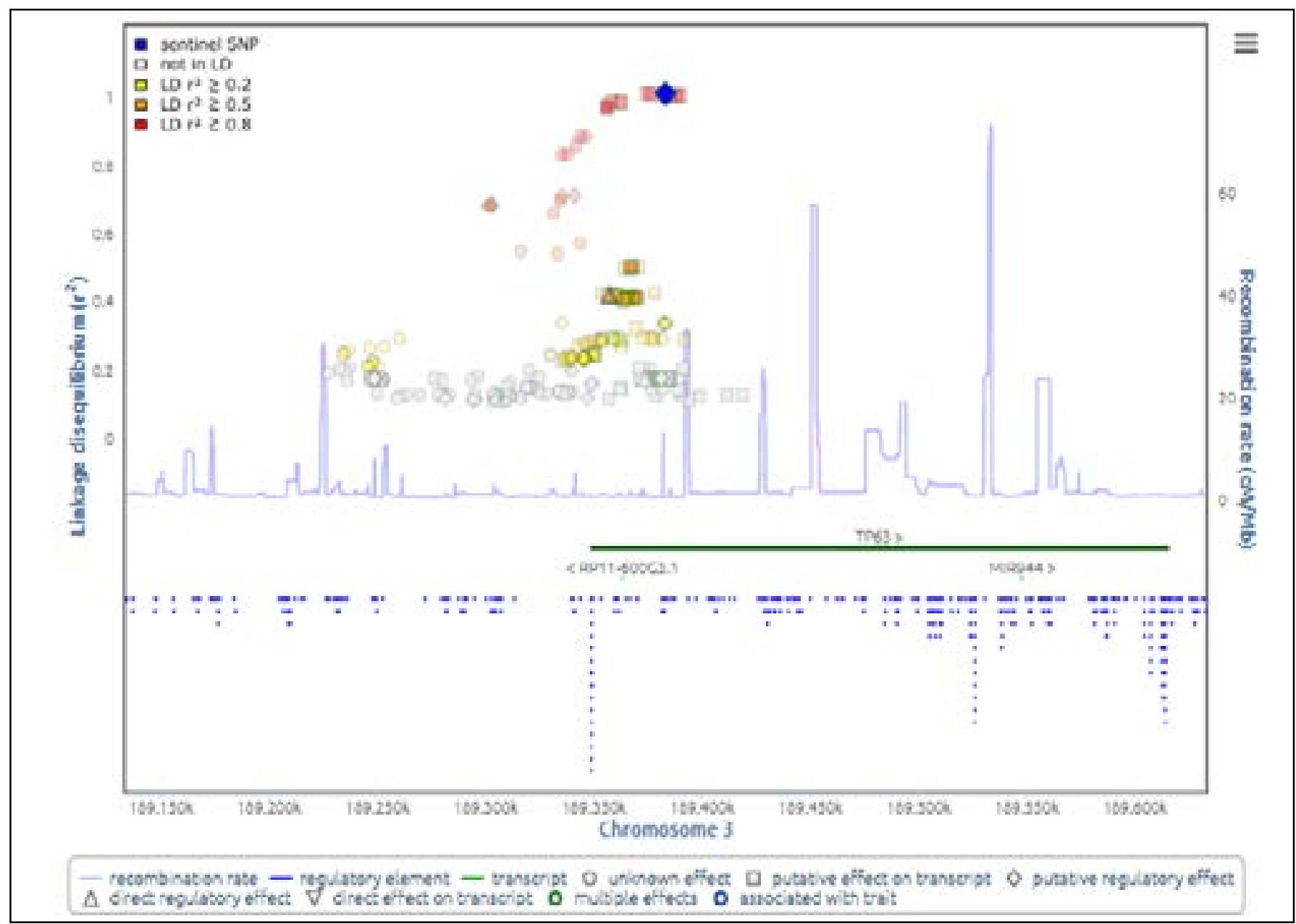

Fig 2: Linkage disequilibrium plot shows the amount of correlation between a sentinel variant (blue colored) and its surrounding variants (red colored). The y-axis signifies the correlation coefficient; the $\mathrm{x}$-axis signifies the chromosomal position of each SNP. The plot symbol of each variant designates its functional observations (http://snipa.helmholtz-muenchen.de).

This variant has also been found associated with the lung cancer of the North Indian population by our group $^{25}$, thus suggesting a potential role in multiple cancers. Our findings suggest that this SNP can be used as diagnostic and prognostic marker for leukemia and other cancer types in the North Indian populations.

\section{Conclusion}

Our findings provide evidence that the variant rs10937405 of TP63 is significantly association with leukemia in the population of Jammu and Kashmir in Northern India. Further studies involving more diverse ethnic groups, particularly from north India will not only validate these findings but will also assist in developing this variant as a biomarker for leukemia screening programs.

\section{Conflict of interest}

None.

\section{Acknowledgment}

$\mathrm{RK}$ and $\mathrm{AB}$ acknowledge the Department of Science \& Technology, Government of India (DST/SSTP/ $\mathrm{J} \& \mathrm{~K} / 459)$ for financial assistance.

\section{Author Contribution}

$\mathrm{RK}$ and $\mathrm{AB}$ planned the work, $\mathrm{AB}$ carried out work all the experiment and wrote the manuscript GRB helped in statistical analysis while SV, BS, DS helped in sampling processes. JS, SS, MK, SV, RS, AB and RK finally refined and approved the manuscript. All authors finally revised and approved the manuscript.

\section{Reference}

1. Solomon B, Parihar N, Ayodele L, Hughes M. Global incidence and prevalence of acute lymphoblastic leukemia: a 10-year forecast Bethlehem. J Blood Disord Transfus. 2017;8:24.

2. Rebecca L. Siegel MPH Kimberly D. Miller MPH 
Ahmedin Jemal DVM P. Cancer statistics, 2018. A cancer Journal of Clinicians. 2018.

3. Siegel RL, Miller KD, Jemal A. Cancer statistics, 2020. CA: A Cancer Journal for Clinicians. 2020;70(1):7-30.

4. Shoket N, Muzamil J, Zargar TB, Wani B, Toka V, Bhat JR, et al. Clinical profile of acute myeloid leukemia in North India and utility of nontransplant measures in its management. Indian Journal of Medical and Paediatric Oncology. 2019;40(5):44.

5. Qurieshi MA, Khan S, Masoodi MA, Qurieshi U, Ain Q, Jan Y, et al. Epidemiology of cancers in Kashmir, India: an analysis of hospital data. Advances in Preventive Medicine. 2016;2016.

6. Wani M, Jan F, Khan N, Pandita K, Khurshid R, Khan $\mathrm{S}$. Cancer trends in Kashmir; common types, site incidence and demographic profiles: National Cancer Registry 2000-2012. Indian Journal of Cancer. 2014;51(2):133. 7. Brisson GD, Alves LR, Pombo-de-Oliveira MS. Genetic susceptibility in childhood acute leukaemias: a systematic review. Ecancer Medical Science. 2015;9.

8. Carvalho DC, Wanderley AV, Junior FARMJ, dos Santos AMR, Leitão LPC, de Souza TP, et al. Association of genes ARID5B, CEBPE and folate pathway with acute lymphoblastic leukemia in a population from the Brazilian Amazon region. Leukemia Research Reports. 2020;13:100188.

9. Zhou X, Liao F, Zhang J, Qin Y, Xu H, Ding Z, et al. Association of the independent polymorphisms in CDKN2A with susceptibility of acute lymphoblastic leukemia. Bioscience Reports. 2018;38(3).

10. Mahjoub S, Chayeb V, Zitouni H, Ghali RM, Regaieg H, Almawi WY, et al. IKZF1 genetic variants rs4132601 and rs11978267 and acute lymphoblastic leukemia risk in Tunisian children: a case-control study. BMC Medical Genetics. 2019;20(1):159.

11. Liao F, Yin D, Zhang Y, Hou Q, Zheng Z, Yang $\mathrm{L}$, et al. Association between PIP4K2A polymorphisms and acute lymphoblastic leukemia susceptibility. Medicine. 2016;95(18).

12. Sherborne AL, Hosking FJ, Prasad RB, Kumar R, Koehler R, Vijayakrishnan J, et al. Variation in CD$\mathrm{KN} 2 \mathrm{~A}$ at 9p21. 3 influences childhood acute lymphoblastic leukemia risk. Nature Genetics. 2010;42(6):492.

13. Miki D, Kubo M, Takahashi A, Yoon K-A, Kim J, Lee GK, et al. Variation in TP63 is associated with lung adenocarcinoma susceptibility in Japanese and Korean populations. Nature Genetics. 2010;42(10):893.

14. Zhang L, Wang X-F, Ma Y-S, Xia Q, Zhang F, Fu D, et al. Quantitative assessment of the influence of TP63gene polymorphisms and lung cancer risk: evidence based on 93,751 subjects. PLoS One. 2014;9(1):e87004.

15. Wang Y, Broderick P, Matakidou A, Vijayakrishnan J, Eisen T, Houlston RS. Variation in TP63 is associated with lung adenocarcinoma in the UK population. Cancer Epidemiology and Prevention Biomarkers. 2011:cebp. 0042.2011.

16. Shiraishi K, Honda T, Kohno T. An overview of genetic polymorphism and lung cancer risk. Adv Cancer Prev. 2016;1(106):2472-0429.1000106.

17. Shimizu M, Kiyotani K, Kunitoh H, Kamataki T, Yamazaki H. Different effects of TERT, TP63, and CYP2A6 polymorphism on individual risk of tobacco-related lung cancer in male Japanese smokers. Journal of Cancer Therapy. 2011;2(05):690.

18. Hosgood HD, Wang W-C, Hong Y-C, Wang J-C, Chen $\mathrm{K}$, Chang I-S, et al. Genetic variant in TP63 on locus 3 q 28 is associated with risk of lung adenocarcinoma among never-smoking females in Asia. Human Genetics. 2012;131(7):1197-203.

19. Wang Y, Broderick P, Matakidou A, Vijayakrishnan J, Eisen T, Houlston RS. Variation in TP63 is associated with lung adenocarcinoma in the UK population. Cancer Epidemiology and Prevention Biomarkers. 2011;20(7):145362.

20. Collavin L, Lunardi A, Del Sal G. p53-family proteins and their regulators: hubs and spokes in tumor suppression. Cell Death \& Differentiation. 2010;17(6):901-11. 21. Chen Y, Peng Y, Fan S, Li Y, Xiao Z-X, Li C. A double dealing tale of $\mathrm{p} 63$ : an oncogene or a tumor suppressor. Cellular and Molecular Life Sciences. 2018;75(6):965-73. 22. Yamaguchi H, Inokuchi K, Tarusawa M, Nakamura K, Nomura T, Dan K. Mutation of P51a/tap63 $\gamma$ gene is associated with blastic crisis in chronic myeloid leukemia. Experimental Hematology. 2000;28(7):76.

23. Hedvat CV, Teruya-Feldstein J, Puig P, Capodieci P, Dudas M, Pica N, et al. Expression of p63 in diffuse large B-cell lymphoma. Applied Immunobistochemistry \& Molecular Morphology. 2005;13(3):237-42.

24. Ntoufa S, Papakonstantinou N, Papazoglou D, Tsagiopoulou M, Pospisilova S, Anagnostopoulos A, et al. TP63 Contributes to the Apoptosis Resistant Phenotype in Aggressive Chronic Lymphocytic Leukemia. American Society of Hematology Washington, DC; 2015.

25. Bhat GR, Bhat A, Verma S, Sethi I, Shah R, Sharma V, et al. Genetic variant rs10937405 of TP63 and susceptibility to lung cancer risk in north Indian population. Journal of Genetics. 2019;98(3):59. 